\title{
Enhancing Agricultural Product Supply Chain Management Using Blockchain Technology: Concept
}

\author{
M A Jawale ${ }^{\mathrm{a}, 1}$, A B Pawar ${ }^{\text {a }}$ \\ ${ }^{a}$ Department of Information Technology, Sanjivani College of Engineering, Kopargaon, India
}

\begin{abstract}
In traditional agricultural supply chain management, due to involvement of many stakeholders in the entire procedure ranging from farmers, retailers to final vendors, it is merely the producer of the agricultural products i.e., farmers get its direct benefit. The middle stakeholders are always more beneficial than farmers and hence, the conditions of farmers are always the same though they sometimes get good earning and it is becoming a very serious concern in India. The major reason behind it, the transparency and traceability of the entire supply chain of this agricultural products journey from farm to vendor shop. In addition, consumers are becoming more conscious of where their food and food products come from. Block chains have distributed ledger technology (DLT) which has potential to provide transparency and trust for agricultural product supply chains at its different stages and even useful for improving its efficiency. This can boost confidence of all stakeholders who are involved in this farming supply chain. This research paper proposes the same concept in its subsequent sections.
\end{abstract}

Keywords - Agricultural Supply Chain Management, Blockchain Technology, Distributed Ledger Technology, Transparency, Traceabiltiy

\section{Introduction}

In today's unpredictable world, everyone is now becoming more health conscious and always curious to know about his or her food details. Mainly, with agricultural food products; consumers want to know where their food comes from, when it is processed, how it is best for their health, freshness of it, and other parameters too. Therefore, many agricultural related businesses are in search of good supply chain management technology-based solutions to enhance food quality, food safety and its traces throughout the entire supply chain of agricultural products. In the agriculture field, there are so many existing technologies in place namely precision farming, crop management systems, IoT based solutions, transport systems which are improving this sector related businesses to get better outcomes related to food production and farming related supply chain. Increase in food demand brings new problems with it like fake or forged agriculture products, which are hovering this supply chain at its different levels. Lack of a properly secured mechanism to ensure transparency and poor efficiency lead towards disadvantages at farmer as well as at consumer's side.

\footnotetext{
${ }^{1}$ M A Jawale,Department of Information Technology, Sanjivani College of Engineering, Kopargaon Email: jawale.madhu@gmail.com.
} 
Eventually, block chains have distributed ledger technology (DLT) which has Potential to provide transparency and trust for agricultural product supply chains at its different stages and even useful for improving its efficiency. This can boost confidence of all stakeholders who are involved in this farming supply chain. The proposed research work is intended to take advantage of block chain technology and want to bring transparency in farming supply chain management, which will improve trust and will give its benefits from farmers, market players to consumers.

\section{Origin of the Research Problem}

The farming supply chains are complicated as well as risky as compared to any other existing business supply chains as its product production relies on natural factors like climatic conditions, pesticides and various diseases -which are difficult to trace, predict and control. This uncertainty brings lack of transparency in this supply chain, Even it requires a lot of manual work to maintain it which slows down financial transactions. Additionally, fake operations may cause at each stage of this supply chain and result in destructive damages to all of its stakeholders including farmers, government, market players and consumers too. As per reported in [1], at each stage of agricultural product supply chain management, there are very serious counterfeit occurs. At manufacturing level, it occurs usually at seed supply, chemical supply and brings huge losses to manufacturers. For farmers, it causes a decrease in crop production, health issues due to fake chemicals in pests, financial losses due to untested fertilizers. Even, for consumers it results in huge losses like decrease in revenue, public health issues, price variations, and unemployment.

This leads towards the proposed research problem as to how to ensure transparency, efficiency in agricultural products supply chain management from seeds to grocery shops and provide a chance to use the potential of block chain technology to encounter it.

\section{Interdisciplinary Relevance}

The proposed system has a large number of applications ranging from agricultural field to data science, machine learning applications which can use this use case for extending its usefulness.

\section{Review of Research and Development in the Subject}

In today's digital world and in continuous population growth, consumers demand services on digital platforms. The consumers are now more interested to know about their foods [2]. Therefore, farmers and agricultural related businesses should use this technology to bring transparency, financial performance improvements and at the same time, it should fulfill demand for the food with high quality. Therefore, the agricultural sector needs to adopt technological changes as early as possible to meet requirements of all stakeholders who depend on the agriculture field and in its supply chain. The major challenge in the agricultural supply chain is its food transportation. With the help of techniques like barcodes, cryptography movement of each product transport and shipping can be observed. The physical movement of this product needs an immutable product and its supply chain process link. Following are existing technologies, which are currently in use to trace the physical movements of the product [3]. 
Use of QR codes on the products and on their packaging: This technology is in place and in use for agricultural products in the supply chain. It needs more regulations to monitor and authenticate from seed bags to a ready grocery product.

Radio Frequency Identifier (RFID) based supply chain management system.

Contactless technology such as NFC agriculture technology IBM crypto anchor for product authenticity [useful but still in its initial development stage]

Blockchain technology is able to trace information at each stage of the farming supply chain and is useful to bring transparency in the system. It provides a secure way to manage and handle data in a distributed, immutable manner which ensures trust on the system and increases system efficiency too. Due to this promising potential of the Blockchain of information traceability, data driven innovativeness, safety; many organizations have been introduced to solutions for food security. The details of few prominent solutions are described in subsequent sections in connection with the proposed research work.

IBM Food Trust: Big IT giant, IBM introduces it as a smart food supply chain which claims support food safety, food quality and traceability. It has multi-faceted features to bring a food ecosystem on a smart platform. [4]

The other proposed solutions and their reviews with current status of these solutions are available in [5]. Most of these solutions are still in the preliminary stage of implementation which includes agricultural insurance, smart agriculture, food supply chain, e-commerce of agricultural products. Also, researchers explore the merits and demerits of Blockchain technology for its effective usage in future research work.

India has its own Blockchain native platform Eleven01 and it has partnership with The International Crops Research Institute for the Semi-Arid Tropics (ICRISAT) and KHETINEXT, a mobile based agricultural solution provider for BlockChain Technology use.

The joint venture of these partners is enabling BlockChain Technology to enhance crop productivity and to raise income for small farmers in India.

This solution is in its initial stage of development [6].

\section{Significance of the study}

The major advantage of this study involves understanding the farming supply chain and its impact on Indian agricultural products traceability from seeds to grocery ready products and how it can be ensured with the potential of the Blockchain Technology with its usage beyond crypto currency to useful technology to enhance lives of farmers in India.

\section{Objective and Research Methodology}

The proposed research work mainly focuses on following objectives during this research work tenure.

To perform a detailed literature survey which will leverage the current state of the agricultural product supply chain system, its pitfalls and impact on all stakeholders from farmers, manufacturers to consumers. In addition, it will give in depth knowledge about Blockchain Technology for implementing the proposed research work. 
To design a solution based on Blockchain Technology for identifying counterfeit in the agri. product supply chain through the following four steps

- Data generation based on IoT at Farm or collection of required crop related details from farmers.

- Supply of grown crops to the food processing industries.

- Supply of processed agricultural products to wholesalers and retailers.

- Consumers can trace the product details and can trace back the supply chain to get information about food products regarding its location details, processing details and quality details.

- To evaluate the performance of a developed system on suitable evaluation parameters.

\section{Research Methodology}

As stated in the Objective section, the following methodology will be applied to bring the proposed solution in real implementation based on stated steps. i.e.

$\circ$ Data generation based on IoT at Farm or collection of required crop related details from farmers.

- Supply of grown crops to the food processing industries.

- Supply of processed agricultural products to wholesalers and retailers.

- Consumers can trace the product details and can trace back the supply chain to get information about food products regarding its location details, processing details and quality details.

The following steps depict the proposed research methodology for the selected research problem solution:

1. Crop details will be collected in Smart Contract of the Public Blockchain either IOT enabled network or through mobile phone application.

2. These entered details will be processed using machine learning algorithms to predict the quality of crop.

3. Details of the quality of crop will be available for Agricultural industries for bidding purposes through its own smart contract.

4. Once a bid is accepted, the payment details will be entered into a smart contract and the concerned crop load will be picked up and will be brought into the agricultural industry for its further processing. Even, auto payment transfer will be available to farmers.

5. The processed agricultural or food product details will be maintained in its own smart contract and traceable to wholesalers for bid.

6. Once a processed agricultural product bid is passed, its payment details will be entered into a smart contract to do auto payment transfer to agricultural industries and shipment will be processed to the concerned wholesaler.

7. At last, once consumers get the agricultural or food products from a wholesaler or retailer; he or she can scan barcode details and can trace contracts for exact location and other details instantly. 
8. Similarly, government agencies or authorities can trace out each and every transaction, costing and other information through these implemented contracts of BlockChain Technology.

\section{Conclusion}

The proposed supply chain traceability system based on BlockChain Technologies can transform the food supply chain from farmers to consumers in the following manner and can provide transparency, trustworthiness and efficiency for agricultural product supply chain systems.

- Simplification and reformation of all steps in the agricultural product supply chain management system.

- Possible tracking and exact food product information along with its complete path information from farmland location to grocery store shelf.

- Elimination of counterfeits in the supply chain and enhance food safety.

- Direct Access to agricultural related financial services to farmers and related businesses.

- Getting smarter agricultural data, for better decision making

- Certification for legal authorities involved in agricultural businesses.

\section{References}

[1]. The report on "Counterfeiting in African Agriculture Inputs - Challenges \& Solutions", Bill and Melinda Gates Foundation in collaboration with Monitor Deloitte, and was used to facilitate a workshop in Nairobi, Kenya on February 14, 2014.

[2]. Shaosheng Jin Yan Zhang, Yining Xu, "Amount of information and the willingness of consumers to pay for food traceability in China", 2017.

[3]. https://www.intellias.com/crop-management-software-for-sustainable-farming/ Accessed Date: $25 / 12 / 2020$

[4]. https://www.ibm.com/in-en/blockchain/solutions/food-trust, Accessed Date : 25/12/2020

[5]. Hang Xiong, Tobias Dalhaus, Puqing Wang and Jiajin Huang, "Blockchain Technology for Agriculture: Applications and Rationale", In Front. Blockchain, 21 February 2020 https://doi.org/10.3389/fbloc.2020.00007

[6]. https://www.downtoearth.org.in/news/agriculture/high-tech-on-the-ground-blockchain-te chnology-to-boost-small-farm-incomes-, Published Date: 28 May 2019 